\title{
Cyber Babies: The Impact of Emerging Technology on the Developing Infant
}

\author{
Ciaran Haughton, Mary Aiken, Carly Cheevers \\ RCSI CyberPsychology Research Centre, RCSI Institute of Leadership, Dublin, Ireland
}

\begin{abstract}
Technology is now ubiquitous with almost 3.2 billion people of the world's current population online (International Telecommunications Union, 2015). Whilst technology offers opportunities for education and entertainment, its impact on vulnerable populations such as the developing infant requires specific, careful consideration. Fourteen percent of infants (aged 6 to 23 months) watch at least two hours of media per day and one third of children under 3 have a television (TV) in their bedroom (Zimmerman, Christakis, \& Meltzoff, 2007a). Twenty-five percent of 3 -year-olds go online daily (Bernstein \& Levine, 2011) and 28\% of 3 to 4-year-olds now use tablet computers (Ofcom, 2014). Children are growing up with a digital foundation, they are interacting with and immersed in cyberspace where they learn, entertain themselves and play. During the first three years of life, the brain creates some 700 new neural connections every second. Synapse formation for key developmental functions such as hearing, language and cognition peak during this time, creating a critical foundation for higher-level functions (Zero to Three, 2015). Very young children are becoming experts at using technology and are true digital natives. Yet what long-term effects will this early exposure have from a developmental perspective? Researchers are now questioning how interactive media may affect children both mentally and physically (American Academy of Paediatrics, 2011; Radesky, Schumacher, \& Zuckerman, 2014). Screen time research has traditionally focused on the impact of TV on children (Linebarger \& Walker, 2005). However, TV is a passive experience and results may not be applicable compared to highly interactive screen technology such as tablets and smartphones, thus the uniqueness of mobile technology needs to be considered. Experts in Canada, France, Australia, Japan, and South Korea have urged limits on children's screen time and legislation has recently been introduced in Taiwan to limit children's unhealthy use of electronic devices (Boseley, 2012; Locker, 2015; Tanimura, Okuma, \& Kyoshima, 2007). Research and recommendations are urgently required regarding the impact of technology on infants and very young children, particularly as the effect of traditional and interactive screen time is potentially developmentally and cyberpsychologically significant in this age group.
\end{abstract}

Keywords: infant development, screen time, technology, education, cyberpsychology

\section{Introduction}

Children as young as 2 years of age are becoming experts at utilising technology and will become the first

Ciaran Haughton, BA Psychology, MSc Forensic Psychology, RCSI CyberPsychology Research Centre, RCSI Institute of Leadership.

Mary Aiken, BA Psychology \& Classics, Dip. Forensic Psychology, MSc CyberPsychology, Distinguished Professor of the Practice of Cyber Analytics, RCSI CyberPsychology Research Centre, RCSI Institute of Leadership.

Carly Cheevers, BA Psychology, PhD Psychology, RCSI CyberPsychology Research Centre, RCSI Institute of Leadership. 
generation of active digital natives from a very early age. However, it is important to consider the effect this early exposure might have on their development. Early childhood is when most of the brain's critical development occurs, thus experiences during this time strongly influence children's future functioning (Irwin, Siddiqi, \& Hertzman, 2007). Accordingly, the increasing amount of access young children have to technology both at home and at school has led many researchers to debate how the use of digital media is affecting them mentally and physically. Overexposure to traditional media use, such as watching TV, has been associated with obesity, sleep problems, aggressive behavior and attention deficits in preschool children (Christakis, Ebel, Rivara, \& Zimmerman, 2004; Christakis, Zimmerman, DiGiuseppe, \& McCarty, 2004; Grøntved \& Hu, 2011; Thompson \& Christakis, 2005). Today, children and teenagers are spending a large amount of time using new technology such as smartphones and iPads, without reducing time spent engaged in traditional forms of screen media like TV. Furthermore, they are routinely engaged with two screens simultaneously (Sigman, 2012). There is concern that this screen time is interfering with traditional social, cognitive, and language building experiences important in developing years. TV and tablet screens do not offer the same tangible experiences as traditional multidimensional practices such as building with blocks - and the effects of these changes on the developing child are still widely unknown. Many experts advise caution. Tisseron (2009) advises that children should not have screen time before the age of 3 while the American Academy of Paediatrics (2011) recommends keeping children under age 2 as "screen-free" as possible due to potential adverse effects on early brain development.

The purpose of the current paper is to consider the impact of exposure to screen time in the first three years of life on the physical, social-emotional, and cognitive development of children. There have been numerous studies conducted on the negative effects of TV screen time on children and key findings in this area will be outlined. The mechanisms by which TV screen time might impact on child development will also be discussed. Tablet and smartphone use is more interactive than the passive engagement of viewing TV and videos, and as of yet, there is little known about their effects on young children. Accordingly, the potential impact of mobile device use on young children will be considered. Research on educational media and the role of the educational media market will be discussed and finally, the need for explicit parental guidelines on screen time for very young children will be considered.

\section{Scale of the Problem}

Today's average home is saturated with technology and young children now have unprecedented access to digital media devices (Ofcom, 2014). A 2013 study on media use in America indicated that $38 \%$ of children under 2 had used a mobile device for media (Zero to Eight, 2013). An (Ofcom, 2013) survey found that among families with children aged 8 or under, $72 \%$ of children had used a mobile device to play games, watch movies or use apps. The same survey also found that $29 \%$ of 3-4 year olds had used a PC or laptop at home, $12 \%$ used a tablet to go online, and of those that did, $58 \%$ went online to access games. Finally, it is claimed that $12.5 \%$ of 3-4 year olds spend over 4 hours a day in front of screens at home (Fletcher, Whitaker, Marino, \& Anderson, 2014). However, TV continues to be the medium children spend most time using (Fletcher et al., 2014; Ofcom, 2013). The American Academy of Child and Adolescent Psychiatry (2011) claim that by the time children have graduated from high school, they will have spent more time in front of the TV than in the classroom. The Zero to Eight: Children's Media Use in America (2013) review found that 0-2 year olds spend approximately one hour a day watching TV and 2-4 year olds are watching up to 90 minutes per day. According to a review by 
Christakis, Ramirez, and Ramirez (2012), the average age children begin to watch TV has decreased from 4 years old to just 5 months old, and that a typical preschool child can spend up to $30 \%-40 \%$ of their waking time in front of TV screens (Christakis et al., 2004; Christakis \& Zimmerman, 2006; Tandon, Zhou, Lozano, \& Christakis, 2011; Vandewater, Rideout, Wartella, Huang, Lee, \& Shim, 2007; Zimmerman \& Christakis, 2007). This amount of screen time can have adverse effects on children's health and development (Christakis, 2009). The effects of TV screen time on a developing child can be pervasive and a number of examples are discussed below.

\section{TV Screen Time and Physical Health}

There has been limited research examining the impact of TV screen time in early childhood on child health outcomes (American Academy of Paediatrics, 2011). However, research in later childhood suggests a concerning link between TV screen time and health issues. Studies have shown an association between TV viewing and body fat in toddlers and young children (Blair et al., 2007; Jackson, Djafarian, Stewart, \& Speakman, 2009). Similarly, Dennison, Erb, and Jenkins (2002) found that higher levels of TV viewing in 1-5 year olds was significantly associated with their likelihood of being overweight, and research has consistently implicated extensive TV screen time with childhood obesity (Harrison, Burns, McGuinness, Heslin, \& Murphy, 2006; He, Irwin, Sangster Bouck, Tucker, \& Pollett, 2005; Subrahmanyam, Kraut, Greenfield, \& Gross, 2000). While it would be expected that the link between time spent watching TV and weight issues was due to a displacement in time spent on physical activity, in fact, studies have shown the sedentary nature of watching TV has a unique relationship with health risks. A study by Jago, Baranowski, Baranowski, Thompson, and Greaves (2005) found that the amount of TV viewing of 3-7 year olds better predicted their Body Mass Index than their levels of physical activity. Similarly, Jackson et al. (2009) found that the level of physical activity of 2-6 year olds did not moderate the relationship between TV screen time and their body fat, and an intervention by Harrison et al. (2006) indicated that decreasing time spent on sedentary activities was just as effective in reducing obesity as increasing physical activity.

Research has also found problematic associations between TV screen time and childhood sleep, though again most studies focus on older children. The first study to examine the longitudinal relationship between TV exposure in early childhood and sleep duration found that higher levels of TV screen time were predictive of shorter sleep durations across infancy and into middle childhood (Cespedes, Gillman, Kleinman, Rifas-Shiman, Redline, \& Taveras, 2014). An earlier cross-sectional study of a nationally representative sample of 2,068 children (4 months to 35 months of age) found a positive association between TV viewing and the likelihood of the child having irregular sleeping schedules (Thompson \& Christakis, 2005). Similarly, sleeping problems in 3-5 year olds have been shown to be associated with watching TV close to bedtime (Garrison, Liekweg, \& Christakis, 2011). This is important to consider as adequate sleep is critical during the child's early life and issues such as short sleep duration and irregular sleep schedules at this time have been associated with future problematic outcomes including language issues, obesity, hyperactivity and reasoning deficits (Touchette, Petit, Tremblay, \& Montplaisir, 2009).

\section{TV Screen Time and Socioemotional Development}

Quality early childhood interpersonal interactions are essential for building relationships, establishing secure attachments and maturing emotionally (Balbernie, 2013; Raval, Goldberg, Atkinson, Benoit, Myhal, 
Poulton, \& Zwiers, 2001; Zeanah, Berlin, \& Boris, 2011). The exposure to TV media on the socioemotional development of young infants is still largely unknown and the research findings in early childhood tend to be inconsistent (Anderson \& Pempek, 2005; Mistry, Minkovitz, Strobino, \& Borzekowski, 2007; Napier, 2013). However, some patterns have emerged which warrant further investigation. An extensive longitudinal study examining the psychosocial effects of early TV exposure on children found that TV viewing at 29 months was predictive of a higher likelihood of peer rejection and victimisation by classmates at 10 years old (Pagani, Fitzpatrick, Barnett, \& Dubow, 2010). Social and emotional skills are learned through regular social interactions (Sigman, 2012) and screen media can interrupt these essential early interactions (Pagani et al., 2010; Radesky et al., 2014; Radesky et al., 2015). The authors suggest that time spent watching TV displaces time which would be spent on early social interactions and that inadequate social skills may develop later in childhood because of this displacement. In one of the first studies to examine the timing of media exposure, Mistry et al. (2007) found early and sustained TV exposure from early childhood to be a risk factor for future behavioural problems including emotional reactivity and aggression.

\section{TV Screen Time and Cognitive Development}

Research has consistently shown negative associations between time spent viewing TV and a range of cognitive outcomes in young children including attention, intelligence and future educational attainment. Research in infancy by Tomopoulos, Dreyer, Berkule, Fierman, Brockmeyer, and Mendelsohn (2010) found negative associations between time spent exposed to TV media at 6 months old and subsequent cognitive ability at 14 months. A longitudinal study in 2004 found that the more TV children watched as infants (aged 1-3), the more likely they were to have attentional problems by age 7 (Christakis et al., 2004). A related study conducted by Zimmerman and Christakis (2007) examined 3,563 children and found that when children under 3 viewed non-educational, violent or even non-violent programming, attentional problems were prevalent when examined five years later. Interestingly, exposure to any type of content at ages 4-5 was not associated with any subsequent attentional difficulties in this study suggesting a critical period between 0-3 for the development of attentional processes. Similarly, the findings of Zimmerman and Christakis (2005) emphasise the importance of the first three years of life for future cognitive development. Their research found adverse effects of TV viewing of children before they were aged 3 on their subsequent cognitive development in reading, mathematics ability, memory and intelligence at 6 and 7 years old. Pagani et al. (2010) found that for every hour of television watched at 29 months, there was a 7\% decrease in teacher-reported classroom engagement at 10 years of age. Classroom engagement in this study measured essential executive functioning skills related to the classroom such as attention, self-discipline and productivity.

Although a number of TV shows, DVDs and video programmes claim to improve language skills in children under 2, a study of 1000 children failed to find any beneficial effects in toddlers aged 17 to 24 months (Zimmerman et al., 2007b). In fact, this study indicated that for infants 8-16 months, each hour per day of viewing baby DVDs/videos was associated with a 17-point decrease in scores on the Communicative Development Inventory (CDI) (Fenson et al., 1993). The evidence actually quite consistently points to delays in language acquisition if children under 2 are exposed to too much screen time. Tomopoulos et al. (2010) found that duration and content of media exposure in 6 month old children was associated with poorer language development at 14 months and an analysis by Zimmerman et al. (2007a) uncovered a large negative association 
between frequent viewing of baby DVDs/videos and the language acquisition of babies aged 8 to 18 months. Another study from Thailand examined language delay in children (15-48 months) and found that children who started watching TV before 12 months, and who spent more than 2 hours a day watching TV, were six times more likely to have language delays (Chonchaiya \& Pruksananonda, 2008). While long term effects on language development are not entirely clear, the short term effects are worrying (American Academy of Paediatrics, 2011).

\section{The Impact of Background TV on Child Outcomes}

Indirect exposure to TV can also have an impact on child development. Background TV refers to adult media content that is on while children are in the room but is unintelligible to them (Lapierre, Piotrowski, \& Linebarger, 2012). Parents can often leave the TV on in the home regardless of whether someone is watching it or not (Parenting in the Age of Digital Technology: A National Survey, 2013; Roberts \& Foehr, 2004). According to Lapierre, Piotrowski, and Linebarger (2012), on average, US children are exposed to 232.2 minutes of background TV on a typical day. Research has found that rapid visual and auditory changes can distract young children from exploration and toy playtime as their attention is directed towards the screen numerous times during a play session (Schmidt, Pempek, Kirkorian, Lund, \& Anderson, 2008). Background TV also reduces the quality of parent-child interaction as parents too can get distracted by what is on the screen and therefore can spend less time engaging with the child (Kirkorian, Pempek, Murphy, Schmidt, \& Anderson, 2009). Cognitive processing, memory and reading comprehension can also be negatively affected by the presence of background TV (Armstrong \& Greenberg, 1990; Barr, Lauricella, Zack, \& Calvert, 2010; Schmidt et al., 2008; Vandewater et al., 2005).

\section{Mechanisms by Which Screen Time Might Impact Development}

There are a number of theories as to how exposure to screen time in infancy and toddlerhood might impact on child development. Firstly, there is the possibility of an indirect impact through the displacement of enriching experiences and activities with caregivers. Engaging in cognitively stimulating activities such as reading and playing with children during this time is associated with positive developmental outcomes. Similarly, it is crucial for caregivers to respond to and scaffold children's vocalisations at this age to facilitate language development (Hart \& Risley, 1995; Shimpi, Gámez, Huttenlocher, \& Vasilyeva, 2007). However, it has been shown that for every hour of TV a child under 2 watches by themselves, 52 less minutes a day are spent interacting with others (Vandewater, Bickham, \& Lee, 2006). TV can impact not only quantity of time spent but also the quality. In the presence of a TV parents have been shown to be less attentive, engaged, spend less time speaking to their children and speak to them in shorter sentences (Christakis, 2009; Kirkorian, Pempek, Murphy, Schmidt, \& Anderson, 2009; Mendelsohn et al., 2008; Tanimura, Okuma, \& Kyoshima, 2007). In fact when Zimmerman et al. (2009) statistically controlled for child-directed parental language, the negative effect of TV viewing on language development was entirely eliminated. Children's linguistic development may be at risk because they are not spending enough time engaging in productive language by verbalising with others, rather listening to TV, which is receptive language (Plowman, McPake, \& Stephen, 2010). Furthermore, Tomopoulos et al. (2007) found a negative association between time spent watching TV by children and the time their caregivers spent reading to them or engaging in learning activities like teaching shapes, letters and numbers. Indeed, the impact on child development may be compounded by the fact that it is these types of 
interactions which can offer an opportunity for parents to verbally engage with their children (Mendelsohn et al., 2010).

Additionally, time spent watching screens can reduce the time children spend engaged in play. Playtime is an important element of infancy and early childhood and in particular is critical in developing problem-solving skills and expressing creativity (Ginsburg, 2007). Vandewater et al. (2006) found that for every hour of TV watched there is $9 \%$ and $11 \%$ less time on weekdays and weekends, respectively, spent in creative play for a child younger than 2 years old. Exposure to background TV also disrupts child's play; they spend less time playing and their attention to play is less focused (Schmidt et al., 2008).

It has been theorized that screen time has a direct impact on neurological functioning through features of the medium itself, and that flashing lights, quick edits and auditory cuts might be over stimulating to developing brains (Anderson \& Pempek, 2005; Christakis, 2009). With regards to TV shows or DVDs aimed at children, rapid scene changes and quick edits are specifically employed to engage infants' orienting response (the reflex that fixes attention to strange sights or sounds). While this keeps them focused on the screen, it is in contrast to the pace of how real life unfolds (Christakis et al., 2012; Christakis, 2009). This can lead to an overstimulation of the developing brain which in turn trains it "to expect intense input making reality underwhelming or even boring by comparison" (Christakis, 2009, p. 12). Research with mice had shown that overstimulation during early life is associated with significantly higher activity levels, risk taking, diminished short-term memory and poorer cognitive functioning (Christakis et al., 2012). Furthermore, the light emitted from TV screens has been shown to impact on melatonin production, suggesting a possible mechanism for sleep disruption (Higuchi, Motohashi, Liu, Ahara, \& Kaneko, 2003; Kubota et al., 2002).

\section{Considering the Impact of Exposure to Mobile Interactive Technology in Early Childhood}

With the advent and proliferation of tablet and smartphone technology, children's main exposure to screen time is no longer limited to TVs in the home. The use of such technology by young children is ever increasing, yet considering the rate of adoption the research examining the impact of these technologies on child development has been lagging behind (Radesky et al., 2015). Within the context of a dearth of research into the impact of interactive technologies on early child development, it is reasonable to assume that using these technologies as a passive medium to watch videos will at least show similar concerning effects on child development. Similarly, it is likely that the aforementioned mechanisms by which TV screen time might be impacting on development, namely through displacement of enriching activities, social interaction and play, and features of the medium itself, would also be implicated in mobile technology use. In fact, evidence from a small study in 2010 has already emerged indicating an inverse relationship between young children's (ages 4-7) engagement with games on tablets or mobile devices and the amount of time they spent in regular play (Chiong \& Shuler, 2010).

However, given the unique characteristics of these technologies, i.e., their portability and interactivity, it is important to consider how they might have a stronger, more pervasive influence on the developing child. The portability of these technologies might serve to exacerbate the issue with more frequent displacement of enriching activities. Of concern is that due to the portability of these technologies they are being used as "virtual pacifiers" (Harding, 2015, p. 1) or "electronic babysitters" (Lerner \& Barr, 2014, p. 2) to keep children occupied during typical daily routines (Radesky et al., 2014; Radesky et al., 2015). This will not only serve to reduce time spent engaged in enriching activities, it also raises serious questions as to the impact on the 
development of self-regulation by children over time. Given the increasing phenomenon of parents attempting to divide their attention between their children and media devices in today's technological society, there is also a concern of how the impact of mobile technology use can affect parents' responsiveness to their children. Even in the presence of background TV, research has shown mothers are less responsive to their children (Schmidt et al., 2008). Therefore, it is not surprising that the only study so far to examine this phenomenon in the use of mobile technologies observed caregivers missing children's bids for attention due to the fact they were engaged with a mobile device at the same time (Radesky et al., 2014). Of particular concern here is how this might impact on infants' attachment styles and child outcomes as caregiver responsiveness is key to secure attachments and positive child functioning (Raval et al., 2001).

Questions also arise as to how the interactive nature of these technologies may impact on the developing infant. Infants develop perceptual knowledge by interacting with the world around them, which has typically been through interaction with others, 3-D toys and objects in their surrounding environment. As their senses mature, they start to coordinate information received from multiple sensory modalities. As such, how will the cues provided to the child from regularly interacting with these technological interfaces during the critical period of brain development impact on the development of depth perception? How will manipulating 2-D objects on a screen affect the development of object perception, and in turn one of the crucial infancy milestones—object permanence?

The convenient size of these technologies mean children will be exposed to screens at a much closer distance which may impact on the development of visual acuity - for which the first two years of life is crucial. Until they develop fully, an infant's visual acuity is limited (Smith, Cowie, \& Blades, 2003). Spending a lot of time looking at screens close-up can cause myopia (short or near-sightedness) and this can occur because children are not spending sufficient time looking at things that are in the distance (Teach Age Kids, 2012). The blue light from smartphones and tablets is known to cause long term damage, although the extent of the damage is still unknown (NZ Herald, 2015). If blue light can negatively impact fully developed eyes, it is important to investigate what impact this light is having on the undeveloped eye sight of infants and toddlers. Furthermore, this light may delay melatonin release significantly more than light from a TV (as TV light decays with distance), thus suggesting a possible impact on sleep quality (Calamaro, Mason, \& Ratcliffe, 2009). To compound this issue, a recent paper by Falbe et al. (2015) examined the differential effects of TV and small screens (smartphones and tablets) on the sleep of fourth and seventh grade students in America. They found that sleeping near a small screen, sleeping with a TV in the room, and the total amount of screen time, were all associated with shorter sleep durations. However, only the presence of a small screen in the bedroom was associated with insufficient rest and poorer sleep quality. The authors state that a small screen device such as a mobile phone can disrupt sleep more because of alerts that can go off during the night compared to a TV which stays off. Finally, the stimulation experienced from various characteristics of these technologies- the screen speed, the sound, the visual design, all need to be considered as to what impact any level of exposure at close range might have on the developing brain during the sensitive period of infancy. The exposure of infants and very young children to mobile technologies is likely, due to their very nature of portability, interactivity and size, to have a more significant impact on their development than the passive viewing of TV. Accordingly, it is crucial for researchers to engage in empirical research in this area to disentangle the possible effects on development in the first three years of life. 


\section{Learning From Screen Media}

This paper has so far considered the negative impact of early childhood exposure to screen time-either passive screen time such as watching TV, or interactively navigating mobile technologies. However, the potentially positive elements of screen media should also be considered. A common reason why parents allow their children to watch TV or play with apps is the learning opportunities these media offer through educational programmes or games (Rideout, 2014). There is some evidence that watching high-quality educational programming can have benefits for children older than 2 years of age in relation to social skills, language skills and school readiness (Lerner \& Barr, 2014). Additionally, a number of studies have reported that programmes such as Sesame Street and Blue's Clues can help improve some educational outcomes in children aged between 3-5 years which can persist into adolescence (Chiong \& Shuler, 2010; Zimmerman et al., 2009; Zimmerman \& Christakis, 2005). However, evidence from research does not appear to support a positive impact of educational programming on younger children. A review by Garrison and Christakis (2005) found claims made by a range of TV programmes of having educational benefits for children 2 years and younger to be unsubstantiated by the evidence. This is due to the "video-deficit" or "transfer-deficit" phenomenon whereby very young children find it more difficult to learn information from a video compared to the same information being taught in a live presentation by a human (American Academy of Paediatrics, 2011; Anderson \& Pempek, 2005; Schmitt \& Anderson, 2002; Sigman, 2012). Furthermore, young children find it difficult to comprehend elements of programs not grounded in their understanding of everyday experience of the world (Lillard, Drell, Richey, Boguszewski, \& Smith, 2015). This can have a negative effect on learning as a very young child's executive function is taxed as they struggle to understand what they are watching (Lerner \& Barr, 2014).

Most of the empirical research on the use of interactive technology has been to examine the potential of learning from apps on smartphones and tablets in older children and adolescents. Findings from the scant research examining the learning of 0-3 year olds using interactive technology have been mixed. Advocates for digital learning believe that although "video deficit" can occur when being exposed to passive media such as TV and DVDs, the same may not be true for interactive media (Guernsey, 2012). An experiment in 2010 offered support to this theory which found that 30-36 month old children who watched a video of a task with an interactive component performed as well as the children who watched a live demonstration of the same task, and performed significantly better than those children who watched only the video (Lauricella, Pempek, Barr, \& Calvert, 2010). The results suggested that children's learning from a screen can be improved by contingent, interactive experiences with media. Similarly, another study indicated that 15 month olds were 22 times more likely to transfer learning from a touch screen device to a real-world 3-D object when their parents actively engaged with them during use (Lerner \& Barr, 2014; Zack, 2010). However, contrary to these findings, a recent experimental study of 2.5-3 year olds indicated that a transfer or video deficit of learning across touch screen content and real life still occurred even in the presence of a live demonstrator who interacted with the touch screen (Moser, Zimmermann, Dickerson, Grenell, Barr, \& Gerhardstein, 2015). This study also indicated that when young children completed a puzzle on the touch screen compared to the 3-D puzzle, they tended to be less efficient and spent more time manoeuvring the 2-D pieces off-task, suggesting a certain level of distraction due to the technology (Moser et al., 2015). Similarly, a study of older children and parents using e-readers found that they became distracted by the technological interactivity of the medium, which then impacted on their story comprehension (Parish-Morris, Mahajan, Hirsh-Pasek, Golinkoff, \& Collins, 2013). Finally, 
exposure to and engagement with age-inappropriate apps by young children may waste valuable cognitive effort on content that is incomprehensible to them (Lillard et al., 2015). Indeed, Chiong and Shuler (2010) found that the capability of learning from educational apps diminished unless children were engaging in age-appropriate apps. Evidently, there is not enough research to support the use of TV, video or interactive technology to promote learning in very young children.

\section{The Infant Educational Media Market}

Despite the lack of evidence supporting screen media for learning in very young children, the infant educational media market has grown into a billion dollar industry. The educational value of such media has been exaggerated to such an extent that in recent years Disney had to provide a refund for one of its "educational" DVDs in light of the fact it showed no benefit to learning (Lewin, 2009). In terms of interactive technologies, industry is actively targeting the 0 to 2 year age group and their parents as consumers of digital media (American Academy of Paediatrics, 2011). A review of the educational app market on iTunes in 2012 found that the early learning toddler app market was the most popular category on the Apple iTunes App Store (Shuler, 2012). There is a lack of regulation in relation to the educational benefit claims made by app developers and TV/video producers. Whilst infant digital content such as apps and software programs might be entertaining, in the absence of robust evidence-based research this content should not be marketed as educational or even developmentally appropriate. The authors propose the creation of an independent, non-profit review service which could make professional assessments of educational media products available to parents free of charge. This is supported by Shuler (2012), who recommends the introduction of standards for products marked as educational to ensure app developers deliver on their educational promises. This would have the benefit of regulating companies who make unsubstantiated claims regarding the educational or developmental merits of their products (Garrison \& Christakis, 2005). Parents commonly perceive educational apps as facilitators to their children's learning (Rideout, 2014), thus standards for products marketed as educational are essential in order for parents to make informed product purchases. Furthermore, if parents allow their young children to engage with technology it is vital that they review the type of programming or games involved (American Academy of Paediatrics, 2011).

\section{Parental Guidelines for Screen Time}

Parents need to be able to make informed decisions about children's media use and they need to understand the consequences of early exposure and overuse. In 2011, the American Academy of Paediatrics reiterated their 1999 statement on limiting the time under 2s spend watching TV, and expanded it to all media including mobile technology (American Academy of Paediatrics, 2011). For older children they advise that only high-quality, age-appropriate, educational programming should be viewed. However, there appears to be evidence of discord between expert guidelines, parental awareness of such guidelines, and their attitudes towards them. A study by Christakis (2009) found that only 6\% of parents were aware of the American Academy of Paediatrics guidelines, while He et al. (2005) found that parents of young children questioned the rationale of such guidelines limiting screen time. A national survey conducted by Northwestern University in 2013 found that just over half of parents (55\%) were unconcerned about the media content their children were exposed to, and in fact generally believed that media on TV and mobile devices can have positive effects on children's academic skills (Parenting in the Age of Digital Technology: A National Survey, 2013). While this 
may be true when a child is at a particular developmental stage, parents do need to be aware of the problems associated with overstimulation in early childhood, and that most studies find no beneficial effects of screen time, particularly in very young children (Linebarger \& Walker, 2005; Zimmerman et al., 2007b). It is vital to improve parents' knowledge in this area as parental attitudes towards technology tend to influence their children's relationships with digital media (Vandewater et al., 2007). There is a lack of comprehensive guidelines for parents, which means that raising a child in an age of ever evolving technology is a challenging prospect, and may account for some confusion and uncertainty (Plowman, McPake, \& Stephen, 2010). Sigman (2012) suggests that medical establishments should offer guidance to parents on the average number of hours per day children should spend viewing screen media, and critically the age at which to start. Sigman (2012) also maintains that screen time consumption should be measured in units similar to alcohol. Perhaps a guide to hours and minutes consumed per day should be developed in order to give parents proper measurable and age-appropriate guidelines. This would help to establish appropriate usage rules in infancy rather than trying to reduce exposure to media in later life (Christakis, 2009).

\section{Conclusion}

This paper considered the developmental impact of passive and interactive screen time exposure in infancy and early childhood. To summarize, traditional media use has been associated with a range of physical, socioemotional and cognitive problems as a possible result of the medium itself and displacement of important developmental activities. It is assumed that if modern mobile technologies are being used in similar ways to traditional media, i.e., to passively watch content, then these negative associations could hypothetically be transferred (Christakis, 2014). However, this paper also questioned the ways in which the unique portability and interactivity of handheld devices might have a stronger effect on the developing child. In addition, the need to regulate the marketing of "educational" media and to inform parents of expert guidelines on this topic were both discussed. There is no sound evidence to suggest very young children, particular those under 2, can learn from screen media, yet the educational media industry targets parents of these children without any regulation. Furthermore, a lack of robust research has meant that clear developmentally appropriate screen media guidelines have not been made widely available to parents, additionally when informed of best practice, parents generally do not appear to comply with same. Further educational directives are therefore urgently required, particularly given the developmentally vulnerable disposition of the under 2 year olds.

To conclude, while recently there has been an increase in literature studying handheld devices and the impact of these from a child developmental perspective (Bittman, Rutherford, Brown, \& Unsworth, 2011; Vandewater et al., 2007), it is nonetheless vital that more research is conducted to investigate the exposure of interactive media on the development of young infants over time (Guernsey, 2012; Sigman, 2012). Some may argue that "judicious use" of interactive media is acceptable for infants under 2 years (Christakis, 2014). However, experts in Canada, France, Australia, Japan, USA, Taiwan and South Korea have urged limits on children's screen time (Boseley, 2012; Tanimura et al., 2007; U.S. Department of Health and Human Services., 2013). Sigman (2012) argues that screen media should be recognised as a major public health issue, and reducing it should become a new priority for child health. However, there are no such guidelines in Ireland or the UK at present. Research, standards and recommendations are urgently required regarding the impact of technology on infants and very young children, particularly as the effect of traditional and interactive screen time is potentially developmentally and cyberpsychologically significant in this age group. 


\section{References}

American Academy of Child and Adolescent Psychiatry. (2011). Children and watching TV. Facts for Families, 54. Retrieved from http://www.aacap.org/AACAP/Families_and_Youth/Facts_for_Families/FActs_for_Families_Pages/Children_And_ Wat_54.aspx

American Academy of Paediatrics. (2011, November 1). Media use by children younger than 2 years. Pediatrics, 128(5), 1040-1045. http://doi.org/10.1542/peds.2011-1753

Anderson, D. R., \& Pempek, T. (2005). Television and very young children. American Behavioral Scientist, 48(5), 505-522. http://doi.org/10.1177/0002764204271506

Armstrong, G. B., \& Greenberg, B. S. (1990). Background television as an inhibitor of cognitive processing. Human Communication Research, 16(3), 355-386. http://doi.org/10.1111/j.1468-2958.1990.tb00215.x

Balbernie, R. (2013). The importance of secure attachment for infant mental health. Journal of Health Visiting, 1(4), $210-217$. http://doi.org/10.12968/johv.2013.1.4.210

Barr, R., Lauricella, A., Zack, E., \& Calvert, S. L. (2010). Infant and early childhood exposure to adult-directed and child-directed relevision programming: Relations with cognitive skills at age four. Merrill-Palmer Quarterly, 56(1), 21-48. http://doi.org/10.1353/mpq.0.0038

Bernstein, L., \& Levine, M. H. (2011). Preface. In A. L. Gutnick, M. Robb, L. Takeuchi, \& J. Kotler (Eds.), Always connected: The new digital media habits of young children. New York: The Joan Ganz Cooney Center at Sesame Workshop. Retrieved from http://asiapacificbcw.org/resources/Children and Digital Media.pdf

Bittman, M., Rutherford, L., Brown, J., \& Unsworth, L. (2011). Digital natives? New and old media and children's outcomes. Australian Journal of Education, 55(2), 161-175. http://doi.org/10.1177/000494411105500206

Blair, N. J., Thompson, J. M. D., Black, P. N., Becroft, D. M. O., Clark, P. M., Han, D. Y., ... Mitchell, E. A. (2007). Risk factors for obesity in 7-year-old European children: The Auckland birthweight collaborative study. Archives of Disease in Childhood, 92(10), 866-871. http://doi.org/10.1136/adc.2007.116855

Boseley, S. (2012, October 9). Ban under-threes from watching television, says study. The Guardian. London. Retrieved from http://www.theguardian.com/society/2012/oct/09/ban-under-threes-watching-television

Calamaro, C. J., Mason, T. B. A., \& Ratcliffe, S. J. (2009). Adolescents living the 24/7 lifestyle: Effects of caffeine and technology on sleep duration and daytime functioning. Pediatrics, 123(6), e1005-1010. http://doi.org/10.1542/peds.2008-3641

Cespedes, E. M., Gillman, M. W., Kleinman, K., Rifas-Shiman, S. L., Redline, S., \& Taveras, E. M. (2014). Television viewing, bedroom television, and sleep duration from infancy to mid-childhood. Pediatrics, 133(5), e1163-e1171. http://doi.org/10.1542/peds.2013-3998

Chiong, C., \& Shuler, C. (2010). Learning: Is there an app for that? Investigations of young children's usage and learning with mobile devices and apps. Investigations of young. New York. Retrieved from http://www-tc.pbskids.org/read/files/cooney_learning_apps.pdf

Chonchaiya, W., \& Pruksananonda, C. (2008). Television viewing associates with delayed language development. Acta Paediatrica, 97(7), 977-982. http://doi.org/10.1111/j.1651-2227.2008.00831.x

Christakis, D. (2009). The effects of infant media usage: What do we know and what should we learn? Acta Paediatrica, 98(1), 8-16. http://doi.org/10.1111/j.1651-2227.2008.01027.x

Christakis, D. A. (2014). Interactive media use at younger than the age of 2 years: Time to rethink the American Academy of Pediatrics guideline? JAMA Pediatrics, 168(5), 399-400. http://doi.org/10.1001/jamapediatrics.2013.5081

Christakis, D. A., Ramirez, J. S. B., \& Ramirez, J. M. (2012). Overstimulation of newborn mice leads to behavioral differences and deficits in cognitive performance. Scientific Reports, 2, 546. http://doi.org/10.1038/srep00546

Christakis, D. A., \& Zimmerman, F. J. (2006). The elephant in the living room: Make television work for your kids. Rodale. Retrieved from https://books.google.com/books?hl=en\&lr=\&id=oQ8AAAAAQBAJ\&pgis=1

Christakis, D., Ebel, B., Rivara, F., \& Zimmerman, F. (2004). Television, video, and computer game usage in children under 11 years of age. The Journal of Pediatrics, 145(5), 652-656. http://doi.org/10.1016/j.jpeds.2004.06.078

Christakis, D., Zimmerman, F., DiGiuseppe, D., \& McCarty, C. (2004). Early television exposure and subsequent attentional problems in children. Pediatrics, 113(4), 708-713. http://doi.org/10.1542/peds.113.4.708

Dennison, B., Erb, T., \& Jenkins, P. (2002). Television viewing and television in bedroom associated with overweight risk among low-income preschool children. Pediatrics, $109(6) . \quad$ Retrieved from http://pediatrics.aappublications.org/content/109/6/1028.short 
Falbe, J., Davison, K. K., Franckle, R. L., Ganter, C., Gortmaker, S. L., Smith, L., ... Taveras, E. M. (2015). Sleep duration, restfulness, and screens in the sleep environment. Pediatrics, 135, 1-9. http://doi.org/10.1542/peds.2014-2306

Fenson, L., Dale, P. S., Reznick, J. S., Thal, D., Bates, E., Hartung, J. P., ... Reilly, J. S. (1993). The MacArthur communicative development inventories: User's guide and technical manual. San Diego: Singular Publishing Group.

Fletcher, E. N., Whitaker, R. C., Marino, A. J., \& Anderson, S. E. (2014). Screen time at home and school among low-income children attending head start. Child Indicators Research, 7(2), 421-436. http://doi.org/10.1007/s12187-013-9212-8

Garrison, M., \& Christakis, D. (2005). A teacher in the living room: educational media for babies, toddlers and preschoolers. Menlo Park, CA. Retrieved from http://kaiserfamilyfoundation.files.wordpress.com/2013/01/7427.pdf

Garrison, M. M., Liekweg, K., \& Christakis, D. A. (2011). Media use and child sleep: The impact of content, timing, and environment. Pediatrics, 128(1), 29-35. http://doi.org/10.1542/peds.2010-3304

Ginsburg, K. R. (2007). The importance of play in promoting healthy child development and maintaining strong parent-child bonds. Pediatrics, 119(1), 182-191. http://doi.org/10.1542/peds.2006-2697

Grøntved, A., \& Hu, F. B. (2011). Television viewing and risk of type 2 diabetes, cardiovascular disease, and all-cause mortality: A meta-analysis. JAMA, 305(23), 2448-2455. http://doi.org/10.1001/jama.2011.812

Guernsey, L. (2012). Interactive screen time for kids: Do educational iPad apps teach toddlers anything? Retrieved from http://www.slate.com/articles/technology/future_tense/2012/05/interactive_screen_time_for_kids_do_educational_ipad_apps teach_toddlers_anything_html

Harding, E. (2015). Headteacher said iPads and iPhones was impeding children's speech. Retrieved from http://www.dailymail.co.uk/news/article-2933988/How-parents-use-iPads-pacify-children-impeding-speech-development-sta rting-school-five-unable-talk-result.html

Harrison, M., Burns, C., McGuinness, M., Heslin, J., \& Murphy, N. (2006). Influence of a health education intervention on physical activity and screen time in primary school children: Switch Off-Get Active. Journal of Science and Medicine in Sport, 9, 388-394. Retrieved from http://www.sciencedirect.com/science/article/pii/S1440244006001423

Hart, B., \& Risley, T. R. (1995). Meaningful differences in the everyday experience of young American children. Baltimore: Brookes.

He, M., Irwin, J. D., Sangster Bouck, L. M., Tucker, P., \& Pollett, G. L. (2005). Screen-viewing behaviors among preschoolers parents' perceptions. American Journal of Preventive Medicine, 29(2), 120-125. http://doi.org/10.1016/j.amepre.2005.04.004

Higuchi, S., Motohashi, Y., Liu, Y., Ahara, M., \& Kaneko, Y. (2003). Effects of VDT tasks with a bright display at night on melatonin, core temperature, heart rate, and sleepiness. Journal of Applied Physiology, 94(5), 1773-1776. http://doi.org/10.1152/japplphysiol.00616.2002

International Telecommunications Union. (2015). ICT facts and figures-The world in 2015. Retrieved from http://www.itu.int/en/ITU-D/Statistics/Pages/facts/default.aspx

Irwin, L. G., Siddiqi, A., \& Hertzman, C. (2007). Early child development: A powerful equalizer (Final report). Geneva: University of British Columbia. Retrieved from http://www.bvsde.paho.org/bvsacd/cd66/EarlyChild/EarlyChild.html

Jackson, D. M., Djafarian, K., Stewart, J., \& Speakman, J. R. (2009). Increased television viewing is associated with elevated body fatness but not with lower total energy expenditure in children. The American Journal of Clinical Nutrition, 89(4), 1031-1036. http://doi.org/10.3945/ajcn.2008.26746

Jago, R., Baranowski, T., Baranowski, J. C., Thompson, D., \& Greaves, K. A. (2005). BMI from 3-6 y of age is predicted by TV viewing and physical activity, not diet. International Journal of Obesity (2005), 29(6), 557-564. http://doi.org/10.1038/sj.ijo.0802969

Kirkorian, H. L., Pempek, T. A., Murphy, L. A., Schmidt, M. E., \& Anderson, D. R. (2009). The impact of background television on parent-child interaction. Child Development, $80(5), \quad$ 1350-1359. http://doi.org/10.1111/j.1467-8624.2009.01337.x

Kubota, T., Uchiyama, M., Suzuki, H., Shibui, K., Kim, K., Tan, X., ... Inoué, S. (2002). Effects of nocturnal bright light on saliva melatonin, core body temperature and sleep propensity rhythms in human subjects. Neuroscience Research, 42(2), 115-122. http://doi.org/10.1016/S0168-0102(01)00310-8

Lapierre, M. A., Piotrowski, J. T., \& Linebarger, D. L. (2012). Background television in the homes of US children. Pediatrics, 130(5), 839-846. http://doi.org/10.1542/peds.2011-2581

Lauricella, A. R., Pempek, T. A., Barr, R., \& Calvert, S. L. (2010). Contingent computer interactions for young children's object retrieval success. Journal of Applied Developmental Psychology, 31(5), 362-369. http://doi.org/10.1016/j.appdev.2010.06.002 
Lerner, C., \& Barr, R. (2014). Screen sense: Setting the record straight research-based guidelines for screen use for children under 3 years old. Washington D.C.

Lewin, T. (2009). No einstein in your crib? Get a refund. New York Times. New York. Retrieved from http://www.nytimes.com/2009/10/24/education/24baby.html

Lillard, A. S., Drell, M. B., Richey, E. M., Boguszewski, K., \& Smith, E. D. (2015). Further examination of the immediate impact of television on children's executive function. Developmental Psychology, 51(6), 792-805.

Linebarger, D. L., \& Walker, D. (2005). Infants' and toddlers' television viewing and language outcomes. American Behavioral Scientist, 48(5), 624-645. http://doi.org/10.1177/0002764204271505

Locker, M. (2015). This place just made it illegal to give kids too much screen time. Retrieved from http://time.com/3682621/this-country-just-made-it-illegal-to-give-kids-too-much-screen-time/

Mendelsohn, A. L., Berkule, S. B., Tomopoulos, S., Tamis-LeMonda, C. S., Huberman, H. S., Alvir, J., \& Dreyer, B. P. (2008). Infant television and video exposure associated with limited parent-child verbal interactions in low socioeconomic status households. Archives of Pediatrics \& Adolescent Medicine, 162(5), 411-417. http://doi.org/10.1001/archpedi.162.5.411

Mendelsohn, A. L., Brockmeyer, C. A., Dreyer, B. P., Fierman, A. H., Berkule-Silberman, S. B., \& Tomopoulos, S. (2010). Do verbal interactions with infants during electronic media exposure mitigate adverse impacts on their language development as toddlers? Infant and Child Development, 19(6), 577-593. http://doi.org/10.1002/icd.711

Mistry, K. B., Minkovitz, C. S., Strobino, D. M., \& Borzekowski, D. L. G. (2007). Children's television exposure and behavioral and social outcomes at 5.5 years: Does timing of exposure matter? Pediatrics, 120(4), $762-769$. http://doi.org/10.1542/peds.2006-3573

Moser, A., Zimmermann, L., Dickerson, K., Grenell, A., Barr, R., \& Gerhardstein, P. (2015). They can interact, but can they learn? Toddlers' transfer learning from touchscreens and television. Journal of Experimental Child Psychology, 137, 137-155. http://doi.org/10.1016/j.jecp.2015.04.002

Napier, C. (2013). How use of screen media affects the emotional development of infants. Primary Health Care, 24(2), 18-25. Retrieved from http://journals.rcni.com/doi/abs/10.7748/phc2014.02.24.2.18.e816

Ofcom. (2013). Children and parents: Media use and attitudes report. Retrieved from http://stakeholders.ofcom.org.uk/binaries/research/media-literacy/october-2013/research07Oct2013.pdf

Ofcom. (2014). Children and parents: Media use and attitudes report. Retrieved from $\mathrm{http}$ //stakeholders.ofcom.org.uk/market-data-research/other/research-publications/childrens/children-parents-oct-14/

Pagani, L. S., Fitzpatrick, C., Barnett, T. A., \& Dubow, E. (2010). Prospective associations between early childhood television exposure and academic, psychosocial, and physical well-being by middle childhood. Archives of Pediatrics \& Adolescent Medicine, 164(5), 425-431. http://doi.org/10.1001/archpediatrics.2010.50

Parenting in the Age of Digital Technology: A National Survey. (2013). Chicago.

Parish-Morris, J., Mahajan, N., Hirsh-Pasek, K., Golinkoff, R. M., \& Collins, M. F. (2013). Once upon a time: Parent-child dialogue and storybook reading in the electronic era. Mind, Brain, and Education, 7(3), $200-211$. http://doi.org/10.1111/mbe.12028

Plowman, L., McPake, J., \& Stephen, C. (2010). The technologisation of childhood? Young children and technology in the home. Children \& Society, 24(1), 63-74. Retrieved from http://onlinelibrary.wiley.com/doi/10.1111/j.1099-0860.2008.00180.x/full

Radesky, J., Miller, A. L., Rosenblum, K. L., Appugliese, D., Kaciroti, N., \& Lumeng, J. C. (2015). Maternal mobile device use during a structured parent-child interaction task. Academic Pediatrics, 15(2), 238-244. http://doi.org/10.1016/j.acap.2014.10.001

Radesky, J. S., Kistin, C. J., Zuckerman, B., Nitzberg, K., Gross, J., Kaplan-Sanoff, M., ... Silverstein, M. (2014). Patterns of mobile device use by caregivers and children during meals in fast food restaurants. Pediatrics, 133(4), e843-849. http://doi.org/10.1542/peds.2013-3703

Radesky, J., Schumacher, J., \& Zuckerman, B. (2014). Mobile and interactive media use by young children: The good, the bad, and the unknown. Pediatrics, 135(1), 1-3. http://doi.org/10.1542/peds.2014-2251

Raval, V., Goldberg, S., Atkinson, L., Benoit, D., Myhal, N., Poulton, L., \& Zwiers, M. (2001). Maternal attachment, maternal responsiveness and infant attachment. Infant Behavior and Development, 24(3), 281-304. http://doi.org/10.1016/S0163-6383(01)00082-0

Rideout, V. (2014). Learning at home: Families' educational media use in America. New York. Retrieved from

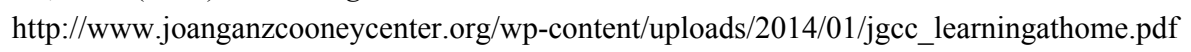


Roberts, D. F., \& Foehr, U. G. (2004). Kids and media in America. Cambridge: Cambridge University Press. Retrieved from https://books.google.com/books?hl=en\&lr=\&id=xeOh0-76SNMC\&pgis=1

Schmidt, M. E., Pempek, T. A., Kirkorian, H. L., Lund, A. F., \& Anderson, D. R. (2008). The effects of background television on the toy play behavior of very young children. Child Development, 79(4), 1137-1151. $\mathrm{http}: / /$ doi.org/10.1111/j.1467-8624.2008.01180.x

Schmitt, K. L., \& Anderson, D. R. (2002). Television and reality: Toddlers' use of visual information from video to guide behavior. Media Psychology, 4(1), 51-76. http://doi.org/10.1207/S1532785XMEP0401_03

Shimpi, P. M., Gámez, P. B., Huttenlocher, J., \& Vasilyeva, M. (2007). Syntactic priming in 3- and 4-year-old children: Evidence for abstract representations of transitive and dative forms. Developmental Psychology, 43(6), 1334-1346.

Shuler, C. (2012). iLearn II: An analysis of the education category on apple's app store. New York. Retrieved from $\mathrm{http}$ //www.joanganzcooneycenter.org/publication/ilearn-ii-an-analysis-of-the-education-category-on-apples-app-store/

Sigman, A. (2012). Time for a view on screen time. Archives of Disease in Childhood, $0(0)$, 1-8. http://doi.org/10.1136/archdischild-2012-302196

Smith, P., Cowie, H., \& Blades, M. (2003). Understanding children's development (4th ed.). Malden: Blackwell Publishing.

Subrahmanyam, K., Kraut, R. E., Greenfield, P. M., \& Gross, E. F. (2000). The impact of home computer use on children's activities. Children and Computer Technology, 10(2), 123-144.

Tandon, P. S., Zhou, C., Lozano, P., \& Christakis, D. A. (2011). Preschoolers' total daily screen time at home and by type of child care. The Journal of Pediatrics, 158(2), 297-300. http://doi.org/10.1016/j.jpeds.2010.08.005

Tanimura, M., Okuma, K., \& Kyoshima, K. (2007). Television viewing, reduced parental utterance, and delayed speech development in infants and young children. Archives of Pediatrics \& Adolescent Medicine, 161(6), 618-619. http://doi.org/10.1001/archpedi.161.6.618-b

Teach Age Kids. (2012). The effect of screens on children's eyes: Myopia and the need to get outdoors. Retrieved from http://www.techagekids.com/2013/09/the-effect-of-screens-on-childrens-eyes.html

Thompson, D. A., \& Christakis, D. A. (2005). The association between television viewing and irregular sleep schedules among children less than 3 years of age. Pediatrics, 116(4), 851-856. http://doi.org/10.1542/peds.2004-2788

Tisseron, S. (2009). Les dangers de la télé pour les bébés. Toulouse: Eres.

Tomopoulos, S., Dreyer, B. P., Berkule, S., Fierman, A. H., Brockmeyer, C., \& Mendelsohn, A. L. (2010). Infant media exposure and toddler development. Archives of Pediatrics \& Adolescent Medicine, 164(12), 1105-1111. http://doi.org/10.1001/archpediatrics.2010.235

Tomopoulos, S., Valdez, P. T., Dreyer, B. P., Fierman, A. H., Berkule, S. B., Kuhn, M., \& Mendelsohn, A. L. (2007). Is exposure to media intended for preschool children associated with less parent-child shared reading aloud and teaching activities? Ambulatory Pediatrics: The Official Journal of the Ambulatory Pediatric Association, 7(1), 18-24. http://doi.org/10.1016/j.ambp.2006.10.005

Touchette, E., Petit, D., Tremblay, R. E., \& Montplaisir, J. Y. (2009). Risk factors and consequences of early childhood dyssomnias: New perspectives. Sleep Medicine Reviews, 13(5), 355-361. http://doi.org/10.1016/j.smrv.2008.12.001

U.S. Department of Health and Human Services. (2013). Healthy people 2020. Retrieved from http://www.healthypeople.gov/prevention-portal-508/initiative/7264

Vandewater, E., Bickham, D., Lee, J., Cummings, H., Wartella, E. A., \& Rideout, V. J. (2005). When the television is always on: Heavy television exposure and young children's development. American Behavioral Scientist, 48(5), 562-577. http://doi.org/10.1177/0002764204271496

Vandewater, E. A., Bickham, D. S., \& Lee, J. H. (2006). Time well spent? Relating television use to children's free-time activities Pediatrics, 117(2), e181-191. http://doi.org/10.1542/peds.2005-0812

Vandewater, E. A., Rideout, V. J., Wartella, E. A., Huang, X., Lee, J. H., \& Shim, M. (2007). Digital childhood: Electronic media and technology use among infants, toddlers, and preschoolers. Pediatrics, 119(5), e1006-1015. http://doi.org/10.1542/peds.2006-1804

Zack, E. (2010). Infant transfer of learning across 2D/3D dimensions: A touch screen paradigm. Washington: Georgetown University. Retrieved from https://repository.library.georgetown.edu/handle/10822/553228

Zeanah, C. H., Berlin, L. J., \& Boris, N. W. (2011). Practitioner review: Clinical applications of attachment theory and research for infants and young children. Journal of Child Psychology and Psychiatry, and Allied Disciplines, 52(8), 819-833. http://doi.org/10.1111/j.1469-7610.2011.02399.x

Zero to Eight. (2013). Zero to eight: Children's media use in America. San Francisco. 
Zero to Three. (2015). Putting infants and toddlers on the path to school readiness: An Agenda for the Administration and 113th Congress. Retrieved from http://www.zerotothree.org/public-policy/federal-policy/2013-federal-policy-agenda.pdf

Zimmerman, F. J., \& Christakis, D. A. (2005). Children's television viewing and cognitive outcomes, 159(July), 619-625.

Zimmerman, F. J., \& Christakis, D. A. (2007). Associations between content types of early media exposure and subsequent attentional problems. Pediatrics, 120(5), 986-992. Retrieved from http://doi.org/10.1542/peds.2006-3322

Zimmerman, F. J., Christakis, D. A., \& Meltzoff, A. N. (2007a). Television and DVD/video viewing in children younger than 2 years. Archives of Pediatrics \& Adolescent Medicine, 161(5), 473-479. Retrieved from http://doi.org/10.1001/archpedi.161.5.473

Zimmerman, F. J., Christakis, D. A., \& Meltzoff, A. N. (2007b). Associations between media viewing and language development in children under age 2 years. The Journal of Pediatrics, 151(4), 364-368. Retrieved from http://doi.org/10.1016/j.jpeds.2007.04.071

Zimmerman, F. J., Gilkerson, J., Richards, J. A., Christakis, D. A., Xu, D., Gray, S., \& Yapanel, U. (2009). Teaching by listening: The importance of adult-child conversations to language development. Pediatrics, 124(1), 342-349. http://doi.org/10.1542/peds.2008-2267 